\title{
Role of Media Creating Desensitization among Viewers Related to Terrorist Acts
}

\section{Ammara lqbal ${ }^{*}$}

Department of Social Sciences, Lahore Garrison University, Pakistan

\begin{abstract}
Media is actually covered the whole world. Media is considered as the fourth pillar of the state. It is very difficult to imagine the life without mass media. Our society depends on the media for getting information and for entertainment. Due to the great advancement and development in media there is a great change among the life of people. It is used to make public opinion, influence and change their attitudes. Media provides services to the viewers who are trying to understand the world. Media has both positive and negative impact on the viewers. Media also effect on the viewer's behavior, more than ever before. Television is the most important medium of electronic media. It is a medium through which people see pictures and also listen the audio simultaneously. It is one of the most up to date means of communication. With the help of TV people can see different events happened in distant places where the access of common people is not possible. TV saves the precious time of busy/modern man. There are many advantages of TV and positive aspects but on the other hand TV has also adverse impacts on people. TV educates or inform the people about the current situation of their country and makes their views or reactions about them. Islamic thinker Dr. Shamsher Ali says, "Television has many good effects but it has also many bad effects. It fully depends on our adoption and adjustment." There are two types of media print or electronic media. Print media has its own importance but due to the boom success of electronic media. It captures all the attention of people in society.
\end{abstract}

Keywords: Society; Communication; Electronic media; Advertise; People; Television; Entertainment

\section{Introduction}

Media is actually covered the whole world. Media is considered as the fourth pillar of the state. It is very difficult to imagine the life without mass media. Our society depends on the media for getting information and for entertainment. Due to the great advancement and development in media there is a great change among the life of people. It is used to make public opinion, influence and change their attitudes. Media provides services to the viewers who are trying to understand the world. Media has both positive and negative impact on the viewers. Media also effect on the viewer's behaviour, more than ever before. Television is the most important medium of electronic media. It is a medium through which people see pictures and also listen the audio simultaneously. It is one of the most up to date means of communication. With the help of TV people can see different events happened in distant places where the access of common people is not possible. TV saves the precious time of busy/modern man. There are many advantages of TV and positive aspects but on the other hand TV has also adverse impacts on people. TV educates or inform the people about the current situation of their country and makes their views or reactions about them. Islamic thinker Dr. Shamsher Ali says, "Television has many good effects but it has also many bad effects. It fully depends on our adoption and adjustment." There are two types of media print or electronic media. Print media has its own importance but due to the boom success of electronic media. It captures all the attention of people in society. After the independence of Pakistan there was only one channel which give the news to public that was Pakistan Television Corporation (PTV). But now technology advances in media have resulted in increases of TV News channels. There are many news channels in Pakistan which give the breaking news of the current issues happened in our country or all around the world. In past such type of incidents happened in the society but on that time people did not inform by such issues. Now a day's media covers every incident that happened in society and informs people by broadcasting the news on TV. Tony Rogers says "Breaking news refers to events that are currently developing or "breaking." Breaking news usually refers to events that are unexpected, such as a plane crash or building fire. The topic of this research is role of media creating desensitization among viewers related to terrorist acts. In media, researcher means Pakistani electronic media. In electronic media, researcher means Pakistani electronic news channels like Geo News, Express News and ARY News etc. Most of information about these incidents comes through the media. In desensitization the researcher means decreased the perception of injury severity, attention to violent issues, negative attitudes towards violence, sympathy for violence victims and increased belief that violence is normative (Figure 1). In this the researchers mean terrorist acts are those activities or incidents which create fear, terror among people. The researchers make following categories of terrorist acts. The researchers found out that how this breaking news of forehead categories of terrorist acts desensitizes viewers at different demographical variables like gender, age, education or frequency (Figure 2).

\section{Statement of the Problem}

The main purpose of the researcher is to investigate that how breaking news of news channels (ARY, GEO, EXPRESS etc.) regarding terrorist acts affect viewers. In this research work the researcher measured viewer's attitude. The researchers found out that how these breaking news regarding terrorist acts desensitize viewers. The researchers used the survey method and study has been done in Lahore.

*Corresponding author: Ammara lqbal, Department of Social Sciences, Lahore Garrison University, Pakistan, Tel: +0332-4798560; E-mail: Ammaraiqbal@lgu.edu.pk

Received August 21, 2017; Accepted August 30, 2017; Published September 06, 2017

Citation: Iqbal A (2017) Role of Media Creating Desensitization among Viewers Related to Terrorist Acts. Arts Social Sci J 8: 297. doi: 10.4172/2151-6200.1000297

Copyright: (c) 2017 lqbal A. This is an open-access article distributed under the terms of the Creative Commons Attribution License, which permits unrestricted use, distribution, and reproduction in any medium, provided the original author and source are credited. 


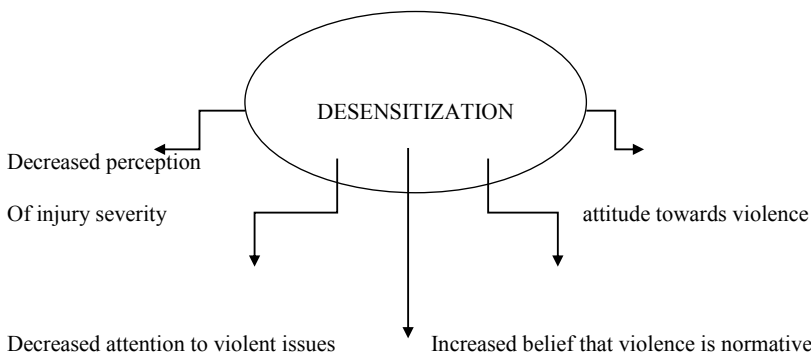

Decreased sympathy for violence victims

Figure 1: Decreased sympathy for violence victims

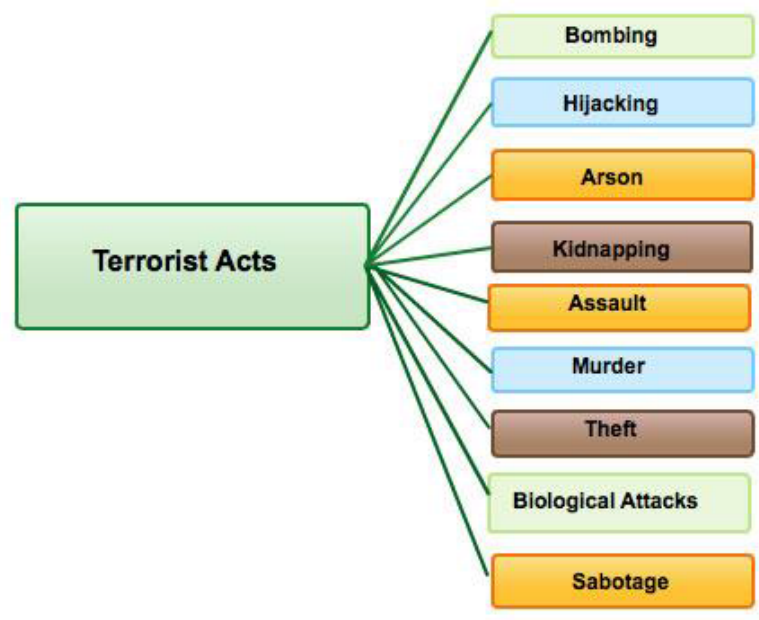

Figure 2: Terrorists acts.

\section{Research objectives}

A. To analyse the role of media.

B. To find out to which extent breaking news of terrorist acts influence viewers behavior.

C. To find out the desensitization on the demographic characteristics of the viewers.

D. To evaluate the importance of media in society.

\section{Research questions}

A. Whether and to which extent breaking news of terrorist acts shape the attitude of viewers?

B. Is there any difference between sympathy level of female and male viewers?

C. Does breaking news of murder change the attitude of viewers?

D. Are less educated viewers increased belief that violence is normative than educated viewers?

E. Are young viewers decreased negative attitude towards violence than the senior citizens viewers?

\section{Research hypothesis}

The researcher has designed the following hypotheses which are as follows:
H1: There is relation between exposure of breaking news of terrorist acts and changing attitude of viewers.

H2: Well educated viewers get less attitude changes than less educated viewers while exposure to breaking news of kidnapping.

H3: Male viewers having more effects than female viewers while exposure to breaking news of murder.

H4: Viewers belong to teenager group are more effected than senior citizens viewers while exposure to breaking news of bombing.

Ho: There is no relationship between exposure of breaking news of terrorist acts and changing attitude of viewers.

Main objective of the study is to pay attention on the effects of breaking news of terrorist acts on the viewers. The researcher wanted to measure the factors because of which people become numb and less reactive towards incidents and this exposure work different on different demographical variables.

\section{Rationale of the Study}

Media is an important part of society. It plays multi-dimensional roles in the society. Recent inventions in media have made its impact more powerful and effective. Today is the era of media. Now-a-days media has many different forms but television is one of the most popular and famous medium among the people. Breaking news of television has a great impact on viewer's behaviour. Everyone is in the race to inform the people first. In the past only PTV channel broadcast the news in detail at 9 o clock. But due to advancement in technology many news channels are established. Today's the news channels achieving he great popularity so it is important to find the relationship between exposure of breaking news and effect of viewers. So the focus of this research is to find out that how and to which extent breaking news of terrorist acts change viewers behavior and how these breaking news changing attitudes and desensitize viewers. The researchers have designed this study to find out the effects of breaking news of terrorist acts on Pakistani viewers living in Lahore. This research was important because there was an effect on the viewers in society and breaking news desensitizes viewers.

\section{Literature Review}

Nicholas et al. [1] conducted a research and in which they conclude that violent video games had a great impact on children then a real life violence. Their research resulted that video games containing violent content have more psychological effect on children and they become desensitize and less empathetic. They have no emotions and feelings towards people who are suffering from pain. Daniel Chandler has analysed different types of studies regarding violence in television and its effect on children. In this the author concluded that the heavy viewership of violent programs show much more aggressive behaviour rather than light. The author has considered desensitization as long term effect. The author has also considered cultivation theory in the long term effects. Bushman and Anderson [2] conducted a study and concluded their study that violent media has a great impact on peoples mind. The violent content of media make the people less sympathetic towards the pain of others and people become numb and less helpful towards suffering people. Reference paper by Craig A. Anderson et al. [3] focuses on the short term effects like observational learning excitation and priming and long term effects including aggression behavior and desensitization by violence watching on youth. It has been supported and analyzed by the empirical research data like cross-sectional and longitudinal research. Huesmann [4] examined the impact of violent 
electronic media on children. He focused on the impact of violent T.V programmes, movies, video tapes or video games. The results of the research also elaborate that the violent games has a great impact on children's mind. He also focuses on long and short term effects on children. In short term effect the priming, arousal and mimicry and in long term effect including desensitization. This research is based on empirical research. Barthlow et al. [5] conducted research "chronic violent video games exposure and desensitization to violent". In this the researchers concluded that the violent content of video games desensitize the children or less empathy towards in their real life. Exposure of these violent video games change the attitude of children towards society. Violent video games numb children. According to the research due to great exposure of violence the children become less helpful to others. Also the violent games played by the teenagers in their daily routine only just for 20 minutes are enough for them to become less sympathetic or different from the real or outside world. She concludes that the heavy dose of media weather it is film, drama, games to children or teenagers become numb or desensitize. Alexandra Lapu et al. [6] states that violent content not only in television but also in video games, movies, music and internet having great impact on children's or adults physiological behavior. It was concluded that children mostly watching T.V or playing video games based on violent content cause arousal of aggressive behaviour or desensitization. This research focuses on the exposure in real life and media violence and desensitization or lack of empathetic attitude and the source being active natured video games, television, movies and internet. The children become numb and become less sympathetic towards other people. Joanne Cantor's [7] paper presented at the annual convention of the American Psychological convention, explores the general limitations of the researches done on the violence watching and the negative emotional responses induced in children and their probable remedies. The author state two categories of emotional responses one is desensitization and hostility and the other is fear and anxieties. $\mathrm{He}$ believes that desensitization could lead individuals to become hostile in their interpersonal relationship. Author has referred researches which prove this relationship. Fear and anxieties are induced in the viewers of violent content especially children although at decreases with age, as they are able to differentiate between reality and fantasy, verbal and nonverbal coping strategies could be used to minimize the effect. Erica Scharrer [8] explores the level of desensitization in her research paper that the violent content weather in the newspaper or in the television had a great impact on the people's mind. Researcher conducted a survey in three regions of U.S and the result was the people who watched violent content on daily basis become numb towards violent content. All the results were positive that conclude desensitization. Emotionally response of Women and men were same but less educated people had great impact than educated people. Barbara Krahe and Ingrid Miller [9] conduct a research in which they examined the links between desensitization to media violent and habitual media violence. They selected two types of clips, sad or funny clips. But the result was that no aggressive behaviour found on the laboratory test. They suggest or observed that only violent content effects on the people and create desensitization. Javed Akram [10] in his article presented his views that there is an age of media and after every 15 minutes there is a breaking news in front of people weather the news are important or not. Due to the great competition among channels $[11,12]$. They bombard the news and people are overdosed by these content and yellow journalism. The media highlight the violent content and bombarded the clips of dead bodies. Such type of violent content numbed the brain of Pakistani people's and less sympathetic towards the victims and pain of people.

\section{Theoretical Framework}

Cultivation theory supports the proposed research as it investigates the images in media content and relationship between exposure to TV and audience attitude and behavior. TV is one of the most important medium or source for spreading news in society. According to Gerbner people who watch TV more than 4 hours called heavy viewers and less than 2 hours called light viewers. According to theorist TV is the medium through which the effects are long lasting terms and according to cultivation theory TV news or programs cultivates the things in the mind of the people and those people who are the heavy viewers highly effected by this. TV cunningly shapes the social reality and presents in front of the people. Researcher have selected this theory in their research that the media news channels present the breaking news of violent content in such way which leave the long term effects and media also cultivate and shape the values and attitude of people. Viewers who watch TV on heavy amount effect by the content of media. The researcher believes that the more exposure of media content the more desensitization occur [13-15].

\section{Desensitization Theory}

The theory of desensitization is most easily applied to violent media. Constant repetitions of violence in the media make people jaded towards violence. The reaction becomes less prominent because as viewers of media are used to seeing explosions, blood and guts on a regular basis. Desensitization is usually measured by both psychological and attitudinal reactions. With the passage of time after watching the violent content people became less reactive towards the violent issues and became less sympathetic towards the victims or injured persons of the violence. Viewers who watch TV on heavy amount became less concerned towards the victims of violence. Heavy exposure of violent content repeatedly the anxiety or aggressive behaviour of peoples changed into desensitization. After watching the violent content people reduce their aggression and feel less concerned or distressing towards the incidents or victims of incidents. A long term of media affects that viewer eventually prone to accepting the real life violence. The viewer's get tolerant the violence in society and considering that the violence is a part of the environment. Their acceptance level of tolerance towards violence shows that the person becomes insensitive member of a society. There are two types of desensitization:

\section{a) Emotional desensitization.}

\section{b) Cognitive desensitization.}

Both emotional and cognitive desensitization make people numbed, less reactive and less sensitive. The viewer's not be aware of that they are being influenced by the content they are watching. The researcher has selected this theory of desensitization because this theory supports the research work of researcher. The researcher believes that the repeated exposure of breaking news related to murder, bomb attacks, arson and violence on women etc. desensitize the viewers. Researcher believes that people who feel emotional, sympathetic, fear, concern and reactive would be subdued into less concerned or insensitive towards victims. Heavy viewers who watch breaking news related to terrorist acts become tolerant towards it and believe that it's a part of society. The study is about role of media (breaking news) creating desensitization among viewers related to terrorist acts. In this researcher wants to know about that the breaking news of terrorist acts affect the viewers and how these breaking news effects on different demographical variables. 


\section{Research Methodology}

In this study, the researchers have adopted the survey method to examine or to explore that to which extent viewers are desensitized by the breaking news of terrorist acts. Before applying the survey method the researchers have deeply analyzed the breaking news that which type of content media present. In this research, before doing the survey method the researchers have analyze the content of breaking news that which type and how media present the breaking news related to terrorist acts. In this the researchers have selected the news channels of electronic media and in these news channels researcher selected the unit of analysis is breaking news of terrorist acts. The researchers divided the terrorist acts into the categories bombing, arson, hijacking, kidnapping, assault, biological attacks and sabotage. The researcher were interested in collecting data from large population but due to time and financial constraint so total 200 male and female viewers of Lahore. Simple random sampling technique will be used. According this technique, the researchers have selected randomly viewers from Lahore.

\section{Characteristic of viewers}

The following chart highlights respondent's gender, education and age.

\section{Gender distribution of viewers}

In this research, the researchers have selected 200 viewers, among them 100 are male and 100 are female viewers (Figures 3 and 4). In this the researchers have selected the viewers which are having different education level. The researcher has selected the both high and low

\section{Series 1}

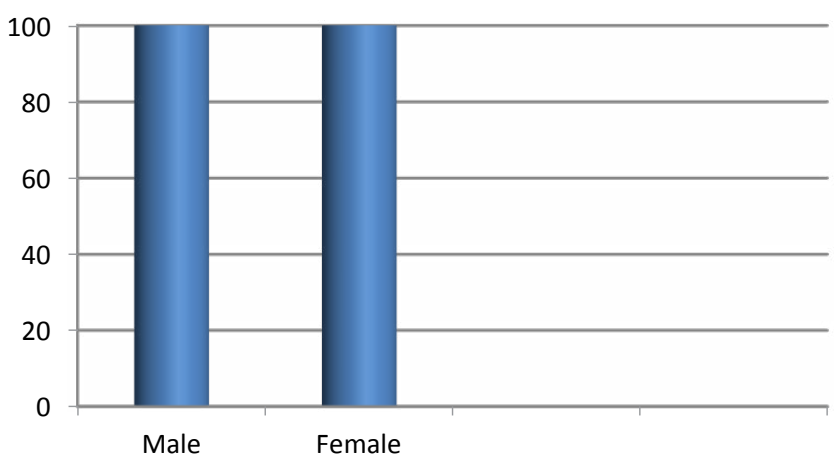

Figure 3: Gender distribution of viewers.

\section{Series 1}

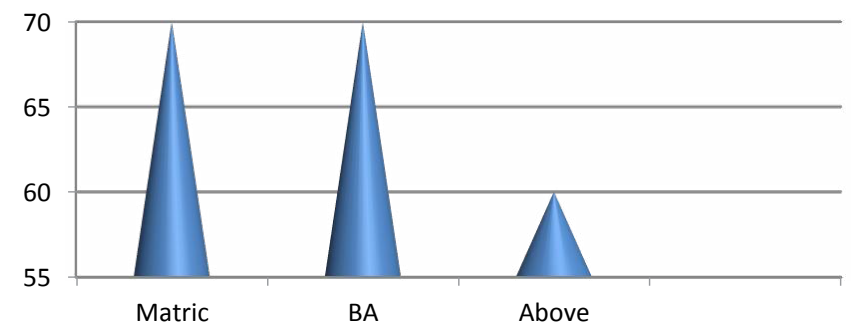

Figure 4: Distribution of education wise viewers.

\section{Series 1}

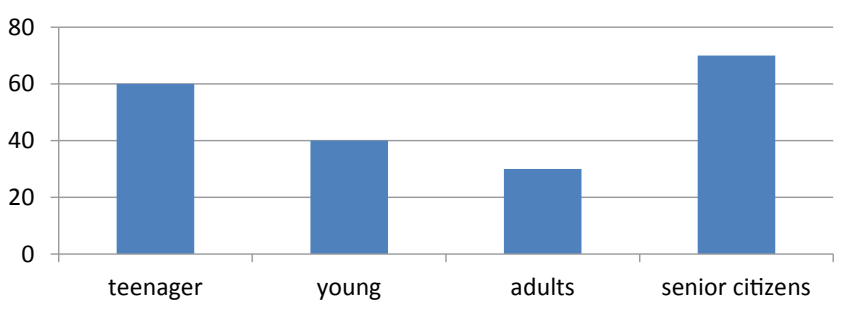

Figure 5: Distribution of age wise viewers.

education viewers. The viewers which are related to metric group are 70,70 viewers from BA and 60 from above BA group (Figure 5). In this the researchers have selected the viewers which are having different age group. The researcher has selected four age type viewers i-e teenager, young, adults and senior citizens. The viewers which are related to teenager group are 60, 40 viewers from young group and 30 from adults group and 70 from senior citizens. In this study "breaking news" is an independent variable. It refers to the phenomena that the more viewers will watch breaking news of terrorist acts, the more desensitization will occur. In this study the dependent variable is "viewers". And In this study the demographical variables are as follows.

\section{Pre testing and reliability test}

One respondent from each category of viewers were being tested by the researcher. The result showed some faults in it so the researcher made them changes in it before finalizing the questionnaire. The researcher tested the questionnaire questions on the Likert's scale.

\section{Application of statistical test}

The following statistics are used by the researcher to analyse the data. The Univariate and Bivariate analysis are being used by the researcher in this research.

\section{Univariate analysis}

In this research, the researchers have examined the relationship between exposure to breaking news of terrorist acts and the changing behavior of viewers. In this research the researchers also found the changing behaviour in the demographic characteristics of age, gender and education. That's why researchers used the univariate analysis and presents the whole data in figures and tables.

\section{Bivariate analysis}

In this research the researchers were testing and verification the hypothesis about the association between exposures to breaking news of terrorist acts and changed in viewers behaviour. In this, researchers applied the Chi-square test. This Chi-square test was applied to see the any type of association between dependent and independent variables.

\section{Procedure for test the hypothesis}

There are some steps to test the hypothesis.

Null hypothesis there is no association between variables,

Alternative hypothesis there is association between variables,

Level of significance $\alpha=0.05$,

Test statistics $2=\sum=1 \quad \sum=1(-) 2$,

Degrees of freedom $v=(-1)(-1)$, 
Critical value $2 ; 1-\alpha$,

Critical region $2>2$ Calculated value $>$ Table value,

Decision rule Reject if 2 (calculated value) $>2$ (Table value).

\section{Hypothesis Testing}

\section{Exposure and effect association}

Now-a-days it is the era of technology and due to this technology advancement media is on its peak in popularity. There is a rapid growth in print or as well as in electronic media. There is a great advancement in news channels. So that's why this study targeted to evaluate the effects of breaking news of terrorist acts on viewer's behaviour. The researcher has selected the sample data and divided it into various demographic characteristics to examine the each hypothesis. This study evaluates the association between exposure to breaking news of terrorist acts and changing behavior of viewers. For this researcher used the Chisquare test. Answers were obtained on the Likert 3-point scale which is mentioned below.

\section{Opinion value: Agree 1, Undecided 2, Disagree 3.}

The answer given by the respondent to the selected category or group it was calculated with respect to the selected category. The response to each question is different. That's why researcher used to compare the scores of the categories of questions.

\section{Changes in viewers attitude}

In this study researchers have conceptualized the attitude of viewers into three factors knowledge, attitude (numbness) and behaviour. The researchers have operationalized each of the factors into six hypothesis and researcher made the questionnaire and in questionnaire each hypothesis has questions in it.

\section{Hypothesis testing result}

The Chi-square result for each hypothesis is summarized in the following section.

\section{Sub hypothesis 1}

There is relation between exposure of breaking news of terrorist acts and changing attitude of viewers. The null hypothesis is rejected at $5 \%$ level of significance (probability null hypothesis rejection) shown in Table 1 Chi-square test value [16]. Therefore the alternative hypothesis of significant association between genders exposure of breaking news of TV and changing the viewer's attitude is accepted (proved). Similarly the Chi-square test value (Table 2) also shows that the null hypothesis is rejected at level of significance $5 \%$ and the alternative hypothesis that association between exposure of breaking news of TV and levels

\begin{tabular}{|c|c|c|c|}
\hline Variables & Chi-square & D.F & Conclusion \\
\hline Pearson Chi-Square & 13.822 & 2 & Significant \\
\hline Total Respondents & 200 & - & - \\
\hline
\end{tabular}

Table 1: Chi-square test for association: Genders exposure of TV breaking news and changing attitude of viewers.

\begin{tabular}{|l|c|c|c|c|}
\hline \multirow{2}{*}{} & \multicolumn{2}{|c|}{ Male } & \multicolumn{2}{c|}{ Female } \\
\cline { 2 - 5 } & Frequency & $\%$ & Frequency & $\%$ \\
\hline Agree & 74 & 74 & 60 & 60 \\
\hline Undecided & 6 & 6 & 25 & 25 \\
\hline Disagree & 20 & 20 & 15 & 15 \\
\hline Total & 100 & & 100 & \\
\hline
\end{tabular}

Table 2: Frequency of gender distribution. of viewer's education is accepted. Moreover the Chi-square test values (Table 3) also reject the null hypothesis at 5\% level of significance and accept the alternative hypothesis that there is relationship between exposures of breaking news of TV on levels of viewers age is accepted. In Table 4 the value shows that the male viewer's percentage between the genders demography is high who agreed that there is greater changes in attitude after the exposure of breaking news of violent content. In Table 5, the value shows that less educated viewer's percentage between the education demography is high and agreed that there is relationship between exposure of breaking news of TV and attitude changing. In the end, Table 6 shows that the percentage of viewers belongs to teenagers between the age demography is high who agreed that there is greater changes in attitude after watching breaking news of TV violent content. The viewers belongs to teenagers are mostly agreed on this whereas the graph of \% decrease when the age increases which means that viewers having less age are mostly less reactive than senior citizens.

\section{Sub hypothesis 2}

Well educated viewers get less attitude changes than less educated viewers while exposure to breaking news of kidnapping. The null hypothesis is rejected at 5\% level of significance (probability null hypothesis rejection) shown in Chi-square test value (Tables 7 and 8). Therefore the alternative hypothesis well educated viewers get less attitude changes than less educated viewers while exposure to breaking news of kidnapping is accepted (proved). Similarly the Chi-square test value (Table 9) also shows that the null hypothesis is rejected at level of significance 5\% and the alternative hypothesis breaking news of TV at levels of viewer's education is accepted. Moreover the Chi-

\begin{tabular}{|l|c|c|c|}
\hline & Chi-square & D.F & Conclusion \\
\hline Pearson Chi-Square & 27.366 & 4 & Significant \\
\hline Total Respondents & 200 & - & - \\
\hline
\end{tabular}

Table 3: Chi-square test for association: Exposure of TV breaking news on levels of education of viewers.

\begin{tabular}{|l|c|c|c|c|c|c|}
\hline & \multicolumn{2}{|c|}{ Matric } & \multicolumn{2}{c|}{ B.A } & \multicolumn{2}{c|}{ Above } \\
\cline { 2 - 7 } & Frequency & $\%$ & Frequency & $\%$ & Frequency & $\%$ \\
\hline Agree & 62 & 88.6 & 44 & 62.9 & 28 & 46.7 \\
\hline Undecided & 3 & 4.3 & 14 & 20 & 14 & 23.3 \\
\hline Disagree & 5 & 7.1 & 12 & 17.1 & 18 & 30 \\
\hline Total & 70 & & 70 & & 60 & \\
\hline \multicolumn{5}{|c|}{ Table 4: Frequency of Education Levels. }
\end{tabular}

\begin{tabular}{|l|c|c|c|}
\hline Variables & Chi-square & D.F & Conclusion \\
\hline Pearson Chi-Square & 12.789 & 6 & Significant \\
\hline Total Respondents & 200 & - & - \\
\hline
\end{tabular}

Table 5: Chi-square test for association: Exposure of TV breaking news on levels of age groups of viewers.

\begin{tabular}{|l|c|c|c|c|c|c|c|c|}
\hline & \multicolumn{2}{|c|}{ Teenager } & \multicolumn{2}{c|}{ Young } & \multicolumn{2}{c|}{ Adults } & \multicolumn{2}{c|}{ Senior citizens } \\
\cline { 2 - 10 } & Frequency & $\%$ & Frequency & $\%$ & Frequency & $\%$ & Frequency & $\%$ \\
\hline Agree & 50 & 83.3 & 24 & 60 & 20 & 66.7 & 40 & 57.1 \\
\hline Undecided & 6 & 10 & 8 & 20 & 3 & 10 & 14 & 20 \\
\hline Disagree & 4 & 6.7 & 8 & 20 & 7 & 23.3 & 16 & 22.9 \\
\hline Total & 60 & & 40 & & 30 & & 70 & \\
\hline
\end{tabular}

Table 6: Determination of gender and frequency.

\begin{tabular}{|c|c|c|c|}
\hline Variables & Chi-square & D.F & Conclusion \\
\hline Pearson Chi-Square & 10.148 & 2 & Significant \\
\hline Total Respondents & 200 & - & - \\
\hline
\end{tabular}

Table 7: Chi-square test for association: Genders exposure of TV breaking news and changing attitude of viewers. 
Citation: Iqbal A (2017) Role of Media Creating Desensitization among Viewers Related to Terrorist Acts. Arts Social Sci J 8: 297. doi: 10.4172/21516200.1000297

Page 6 of 9

square test values (Table 1) also reject the null hypothesis at $5 \%$ level of significance and accept the alternative hypothesis exposures of breaking news of TV on levels of viewer's age is accepted. In Table 8, the value shows that the female viewer's percentage between the genders demography is high who agreed that kidnapping news create fear. In Table 9, the value shows that educated viewer's percentage between the education demography is high and agreed that well educated viewers get less attitude changes than less educated viewers while exposure to breaking news of kidnapping. In the end, Tables 10 and 11 shows that the percentage of viewers belongs to senior citizens between the age demography is high who agreed that well educated viewers get less attitude changes than less educated viewers while exposure to breaking news of kidnapping.

\section{Sub hypothesis 3}

Male viewers having more effects than female viewers while exposure to breaking news of murder. The null hypothesis is rejected at $5 \%$ level of significance (probability null hypothesis rejection) shown in Chi-square test value (Table 11). Therefore the alternative hypothesis male viewers having more effects than female viewers while exposure to breaking news of murder is accepted (proved). Similarly the Chi-square test value (Table 12) also shows that the null hypothesis is rejected at level of significance $5 \%$ and the alternative hypothesis male viewers having more effects than female viewers while exposure to breaking news of murder at levels of viewer's education is accepted. Moreover the Chi-square test values (Table 13) also reject the null hypothesis at 5\% level of significance and accept the alternative hypothesis that male viewers having more effects than female viewers while exposure to breaking news of murder on levels of viewer's age is accepted. In Table 14, the value shows that the male viewer's percentage between the genders demography is high who agreed that they feel not emotional than female viewers. In Table 15, the value shows that

\begin{tabular}{|l|c|c|c|c|}
\hline \multirow{2}{*}{} & \multicolumn{2}{|c|}{ Male } & \multicolumn{2}{c|}{ Female } \\
\cline { 2 - 5 } & Frequency & $\%$ & Frequency & $\%$ \\
\hline Agree & 13 & 13 & 23 & 23 \\
\hline Undecided & 10 & 10 & 1 & 1 \\
\hline Disagree & 77 & 77 & 76 & 76 \\
\hline Total & 100 & & 100 & \\
\hline
\end{tabular}

Table 8: Chi-square test for association: Genders exposure of TV breaking news and changing attitude of viewers.

\begin{tabular}{|c|c|c|c|}
\hline Variables & Chi-square & D.F & Conclusion \\
\hline Pearson Chi-Square & 15.457 & 4 & Significant \\
\hline Total Respondents & 200 & - & - \\
\hline
\end{tabular}

Table 9: Chi-square test for association: Exposure of TV breaking news on levels of education of viewers.

\begin{tabular}{|l|c|c|c|c|c|c|}
\hline & \multicolumn{2}{|c|}{ Matric } & \multicolumn{2}{c|}{ B.A } & \multicolumn{2}{c|}{ Above } \\
\cline { 2 - 7 } & Frequency & $\%$ & Frequency & $\%$ & Frequency & $\%$ \\
\hline Agree & 6 & 8.6 & 10 & 14.3 & 20 & 33.3 \\
\hline Undecided & 3 & 4.3 & 4 & 5.7 & 4 & 6.7 \\
\hline Disagree & 61 & 87.1 & 56 & 80 & 36 & 60 \\
\hline Total & 70 & & 70 & & 60 & \\
\hline
\end{tabular}

Table 10: Chi-square test for association: Exposure of TV breaking news on levels of education of viewers.

\begin{tabular}{|c|c|c|c|}
\hline Variables & Chi-square & D.F & Conclusion \\
\hline Pearson Chi-Square & 7.603 & 6 & Significant \\
\hline Total Respondents & 200 & - & - \\
\hline
\end{tabular}

Table 11: Chi-square test for association: Exposure of TV breaking news on levels of age groups of viewers.

\begin{tabular}{|l|c|c|c|c|c|c|c|c|}
\hline & \multicolumn{2}{|c|}{ Teenager } & \multicolumn{2}{c|}{ Young } & \multicolumn{2}{c|}{ Adults } & \multicolumn{2}{c|}{ Senior citizens } \\
\cline { 2 - 10 } & Frequency & $\%$ & Frequency & $\%$ & Frequency & $\%$ & Frequency & $\%$ \\
\hline Agree & 10 & 16.7 & 9 & 22.5 & 3 & 10 & 14 & 20 \\
\hline Undecided & 0 & 0 & 3 & 7.5 & 2 & 6.7 & 6 & 8.6 \\
\hline Disagree & 50 & 83.3 & 28 & 70 & 25 & 83.3 & 50 & 71.4 \\
\hline Total & 60 & & 40 & & 30 & & 70 & \\
\hline
\end{tabular}

Table 12: Chi-square test for association: Exposure of TV breaking news on levels of age groups of viewers.

\begin{tabular}{|c|c|c|c|}
\hline Variables & Chi-square & D.F & Conclusion \\
\hline Pearson Chi-Square & 16.216 & 2 & Significant \\
\hline Total Respondents & 200 & - & - \\
\hline
\end{tabular}

Table 13: Chi-square test for association: Genders exposure of TV breaking news and changing attitude of viewers.

\begin{tabular}{|l|c|c|c|}
\hline \multirow{2}{*}{} & \multicolumn{2}{|c|}{ Male } & Female \\
\cline { 2 - 4 } & Frequency & $\%$ & Frequency \\
\hline Agree & 75 & 75 & 56 \\
\hline Undecided & 4 & 4 & 23 \\
\hline Disagree & 21 & 21 & 21 \\
\hline Total & 100 & & 100 \\
\hline
\end{tabular}

Table 14: Chi-square test for association: Genders exposure of TV breaking news and changing attitude of viewers.

\begin{tabular}{|c|c|c|c|}
\hline Variables & Chi-square & D.F & Conclusion \\
\hline Pearson Chi-Square & 28.933 & 4 & Significant \\
\hline Total Respondents & 200 & - & - \\
\hline
\end{tabular}

Table 15: Chi-square test for association: Exposure of TV breaking news on levels of education of viewers.

\begin{tabular}{|l|c|c|c|c|c|c|}
\hline & \multicolumn{2}{|c|}{ Matric } & \multicolumn{2}{c|}{ B.A } & \multicolumn{2}{c|}{ Above } \\
\cline { 2 - 7 } & Frequency & $\%$ & Frequency & $\%$ & Frequency & $\%$ \\
\hline Agree & 60 & 85.7 & 46 & 65.7 & 25 & 41.7 \\
\hline Undecided & 6 & 8.6 & 8 & 11.4 & 13 & 21.7 \\
\hline Disagree & 4 & 5.7 & 16 & 22.9 & 22 & 36.6 \\
\hline Total & 70 & & 70 & & 60 & \\
\hline
\end{tabular}

Table 16: Chi-square test for association: Exposure of TV breaking news on levels of education of viewers.

\begin{tabular}{|c|c|c|c|}
\hline Variables & Chi-square & D.F & Conclusion \\
\hline Pearson Chi-Square & 19.306 & 6 & Significant \\
\hline Total Respondents & 200 & - & - \\
\hline
\end{tabular}

Table 17: Chi-square test for association: Exposure of TV breaking news on levels of age groups of viewers.

less educated viewer's percentage between the education demography is high and agreed that who agreed that they feel not emotional than female viewers. In the end, Tables 16 and 17 show that the percentage of viewers belongs to teenagers between the age demography is high who agreed that there is greater changes in behaviour after watching breaking news [17]. The viewers belongs to teenagers are mostly agreed on this whereas the graph of percentage decrease when the age increases which means that viewers having less age are mostly less reactive than senior citizens (Table 18).

\section{Sub hypothesis 4}

Viewers belong to teenager group are more effected than senior citizens viewers while exposure to breaking news of bombing. The null hypothesis is rejected at 5\% level of significance (probability null hypothesis rejection) shown in Chi-square test value (Table 19). Therefore the alternative hypothesis exposure to breaking news of bombing between genders is accepted (proved). Similarly the Chi- 


\begin{tabular}{|l|c|c|c|c|c|c|c|c|}
\hline & \multicolumn{2}{|c|}{ Teenager } & \multicolumn{2}{c|}{ Young } & \multicolumn{2}{c|}{ Adults } & \multicolumn{2}{c|}{ Senior citizens } \\
\cline { 2 - 11 } & Frequency & $\%$ & Frequency & $\%$ & Frequency & $\%$ & Frequency & $\%$ \\
\hline Agree & 49 & 81.7 & 25 & 62.5 & 20 & 66.7 & 37 & 52.9 \\
\hline Undecided & 8 & 13.3 & 7 & 17.5 & 1 & 3.3 & 11 & 15.7 \\
\hline Disagree & 3 & 5 & 8 & 20 & 9 & 30 & 12 & 31.4 \\
\hline Total & 60 & & 40 & & 30 & & 70 & \\
\hline
\end{tabular}

Table 18: Chi-square test for association: Exposure of TV breaking news on levels of age groups of viewers.

\begin{tabular}{|c|c|c|c|}
\hline Variables & Chi-square & D.F & Conclusion \\
\hline Pearson Chi-Square & 11.293 & 2 & Significant \\
\hline Total Respondents & 200 & - & - \\
\hline
\end{tabular}

Table 19: Chi-square test for association: Genders exposure of TV breaking news and changing attitude of viewers.

\begin{tabular}{|l|c|c|c|}
\hline \multirow{2}{*}{} & \multicolumn{2}{|c|}{ Male } & Female \\
\cline { 2 - 4 } & Frequency & $\%$ & Frequency \\
\hline Agree & 78 & 78 & 56 \\
\hline Undecided & 8 & 8 & 22 \\
\hline Disagree & 14 & 14 & 22 \\
\hline Total & 100 & & 100 \\
\hline
\end{tabular}

Table 20: Chi-square test for association: Genders exposure of TV breaking news and changing attitude of viewers.

\begin{tabular}{|c|c|c|c|}
\hline Variables & Chi-square & D.F & Conclusion \\
\hline Pearson Chi-Square & 37.271 & 4 & Significant \\
\hline Total Respondents & 200 & - & - \\
\hline
\end{tabular}

Table 21: Chi-square test for association: Exposure of TV breaking news on levels of education of viewers.

square test value (Table 20) also shows that the null hypothesis is rejected at level of significance $5 \%$ and the alternative hypothesis that exposure to breaking news of bombing at levels of viewer's education is accepted. Moreover the Chi-square test values (Table 21) also reject the null hypothesis at $5 \%$ level of significance and accept the alternative hypothesis at levels of viewer's age is accepted. In Table 22, the value shows that the male viewer's percentage between the genders demography is high who agreed towards breaking news of bombing in Table 23, the value shows that less educated viewer's percentage between the education demography is high and agreed percentage decreases as the viewers education level rose. In the end, Table 24 shows that the percentage of viewers belongs to teenagers between the age demography is high who agreed on this whereas the graph of $\%$ decrease when the age increases which means that viewers having less age are mostly less reactive than senior citizens.

\section{Discussion and Findings}

\section{Major findings of hypothesis testing}

The major findings of the hypothesis testing are given below. In this study the major hypothesis was "There is relation between exposures of breaking news of terrorist acts, the greater changes in viewer's attitude." The researcher wanted to find out the effects of breaking news of terrorist acts on viewer's attitude. In this study the researcher has divided the dependent variable into 3 elements. First major hypothesis was "The more exposure of breaking news of terrorist acts, the greater changes in viewer's attitude." The researcher analyzed the data by using the Chi-square test to find the association between the exposure of breaking news and viewers changing attitude and it concluded the more exposure of breaking news that more attitude change in their attitudes. Findings revealed that all sub-hypotheses statistically approved the major hypothesis First sub hypothesis was

\begin{tabular}{|l|c|c|c|c|c|c|}
\hline & \multicolumn{2}{|c|}{ Matric } & \multicolumn{2}{c|}{ B.A } & \multicolumn{2}{c|}{ Above } \\
\cline { 2 - 7 } & Frequency & $\%$ & Frequency & $\%$ & Frequency & $\%$ \\
\hline Agree & 64 & 91.4 & 45 & 64.3 & 25 & 41.7 \\
\hline Undecided & 2 & 2.9 & 13 & 18.6 & 15 & 25 \\
\hline Disagree & 4 & 5.7 & 12 & 17.1 & 20 & 33.3 \\
\hline Total & 70 & & 70 & & 60 & \\
\hline
\end{tabular}

Table 22: Chi-square test for association: Exposure of TV breaking news on levels of education of viewers.

\begin{tabular}{|c|c|c|c|}
\hline Variables & Chi-square & D.F & Conclusion \\
\hline Pearson Chi-Square & 20.634 & 6 & Significant \\
\hline Total Respondents & 200 & - & - \\
\hline
\end{tabular}

Table 23: Chi-square test for association: Exposure of TV breaking news on levels of age groups of viewers.

\begin{tabular}{|l|c|c|c|c|c|c|c|c|}
\hline & \multicolumn{2}{|c|}{ Teenager } & \multicolumn{2}{c|}{ Young } & \multicolumn{2}{c|}{ Adults } & \multicolumn{2}{c|}{ Senior citizens } \\
\cline { 2 - 11 } & Frequency & $\%$ & Frequency & $\%$ & Frequency & $\%$ & Frequency & $\%$ \\
\hline Agree & 51 & 85 & 26 & 65 & 18 & 60 & 39 & 55.7 \\
\hline Undecided & 3 & 5 & 4 & 10 & 9 & 30 & 14 & 20 \\
\hline Disagree & 6 & 10 & 10 & 25 & 3 & 10 & 17 & 24 \\
\hline Total & 60 & & 40 & & 30 & & 70 & \\
\hline
\end{tabular}

Table 24: Chi-square test for association: Exposure of TV breaking news on levels of age groups of viewers.

"There is relation between exposure of breaking news of terrorist acts and changing attitude of viewers." Findings revealed that in Table 2, the value shows that the male viewer's percentage between the genders demography is high who agreed that there is greater changes in attitude after the exposure of breaking news of violent content. In Table 4 , the value shows that less educated viewer's percentage between the education demography is high and agreed that there is relationship between exposure of breaking news of TV and attitude changing. In the end, Table 6 shows that the percentage of viewers belongs to teenagers between the age demography is high who agreed that there is greater changes in attitude after watching breaking news of TV violent content. The viewers belongs to teenagers are mostly agreed on this whereas the graph of \% decrease when the age increases which means that viewers having less age are mostly less reactive than senior citizens $[18,19]$. The next hypothesis was assumed that "Well educated viewers get less attitude changes than less educated viewers while exposure to breaking news of kidnapping." Findings revealed that in Table 8 the value shows that the female viewer's percentage between the genders demography is high who agreed that kidnapping news create fear. In Table 10, the value shows that educated viewer's percentage between the education demography is high and agreed that well educated viewers get less attitude changes than less educated viewers while exposure to breaking news of kidnapping. In the end, Table 12 shows that the percentage of viewers belongs to senior citizens between the age demography is high who agreed that well educated viewers get less attitude changes than less educated viewers while exposure to breaking news of kidnapping. Next hypothesis was "Male viewers having more effects than female viewers while exposure to breaking news of murder." Findings revealed that in Table 14 the value shows that the male viewer's percentage between the genders demography is high who agreed that they feel not emotional than female viewers. In Table 16, the value shows that less educated viewer's percentage between the education demography is high and agreed that who agreed that they feel not emotional than female viewers. In the end, the Table 18 shows that the percentage of viewers belongs to teenagers between the age demography is high who agreed that there is greater changes in behavior after watching breaking news. The viewers belongs to teenagers are mostly agreed on this whereas the graph of percentage decrease when the age increases which means that 
viewers having less age are mostly less reactive than senior citizens. Next hypothesis was "Viewers belong to teenager group are more effected than senior citizens viewers while exposure to breaking news of bombing." Findings revealed that in Table 20, the value shows that the male viewer's percentage between the genders demography is high who agreed towards breaking news of bombing in Table 22, the value shows that less educated viewer's percentage between the education demography is high and agreed percentage decreases as the viewers education level rose. In the end, Table 24 shows that the percentage of viewers belongs to teenagers between the age demography is high who agreed on this whereas the graph of \% decrease when the age increases which means that viewers having less age are mostly less reactive than senior citizens. The findings of hypothesis confirmed the study and proved that "The more exposure of breaking news of terrorist acts, the greater changes in viewer's attitude." There is an association between breaking news of terrorist acts and its effects on viewer's attitude. The study revealed that the respondents desensitized through breaking news and the news channels content (breaking news) have greater effect on society and by using this type of medium or media content the attitude and behaviour of people can easily be molded. In present study the researchers also applied the Desensitization Theory which suggests that how media change or affects the attitude or behavior of viewers. This theory is relevant to this study.

\section{Conclusion and Recommendation}

Pakistan experienced the rapid growth or progress in media especially in news channels. There are a lot of news channels which aware the people every single incident took place around Pakistan. So this study targeted to find out The effects of TV breaking news of terrorist acts on behavior of viewers. Today we are living in the era of media. There is bombardment of news on viewers. The researchers have a target to find out the changes in viewers attitude linked to the breaking news of terrorist acts or not through the bivariate analysis. The confirmation by the earlier researchers all over the world is the basis of the study that media content changes the attitude of viewers. In this research the researchers found the relationship between the exposure of breaking news and change in viewers attitude. For this research, the researcher has selected the breaking news of terrorist acts because in our Pakistani society, every person has curiosity to know about what happened in their surroundings. That's why researchers wanted to know about that there is any relationship after watching breaking news of terrorist acts between people whom watch TV and their attitudes or reaction tent to change into desensitization. The researchers have selected cultivation or desensitization theory for this research. Media cultivate and shape up the reality and present the molded material in front of people. And after watching such type of content people become less reactive or less sensitive towards the violent content. This theory also discussed that how media content desensitize viewers and change their attitude reactive into less reactive and concern into less concerned viewers. The researchers havr conducted this study during 2016 and the researchers collected the data through survey method. Questionnaire was used by the researcher as a tool for data collection. Questionnaire was made by researcher in English and Urdu both languages because the respondents who belong to low educated sample were not able to read the questionnaire written in English language. In this study the total sample was 200. The researchers selected three demographic variables gender, age and education. In gender researchers selected male and female, in age group selected teenagers, young, adults and senior citizens, and in education group selected high and low educated sample is selected. In this researchers have used the statistical package of social sciences SPSS version 17.0). for analyze the data and the researcher used the Chi-square test to analyze the data and the results shown into general and testing findings. The general findings concluded that many of people desensitize after watching breaking news of terrorist acts or violent content repeatedly. This study proves that breaking news changes the attitude of viewers on heavy amount. The findings of the study also concluded that $67 \%$ viewers agreed violent content increased people belief that violence is normative so the analysis is exposed that the violent content make people less concerned and their belief that violence is present in the surroundings. The findings of the study also concluded that $64 \%$ viewers agreed that people easily accept increasing violence in society because there are a lot of channels which broadcast the news in different ways people easily accept those violence in their lives. The findings of the study also concluded that $18 \%$ viewers agreed that breaking news of kidnapping creating fear among people whereas $5 \%$ were undecided $76 \%$ were disagree on this. The data shows that female viewers feel fear watching news of kidnapping than male viewers. Then percentage also shows that female viewers have a soft heart and feel fear but male viewers become less protective and tolerant towards such type of news. The findings of the study also concluded that $65 \%$ viewers agreed that people not feel emotional after watching breaking news of murder whereas. The data shows that male viewers not feel emotional after watching breaking news of murder than female viewers The findings of the study also concluded that $70 \%$ viewers agreed that people feel less concerned towards biological attacks. Percentage also shows that viewers belong to low education feel less concerned than viewers belong to BA and above category. On the other hand, viewers belonging to teenager more feel less concerned than other age groups. The findings of the study also concluded that $67 \%$ viewers agreed that bombardment of breaking news make people less reactive towards bomb blasts. The data shows that male viewers become less reactive towards news of bomb blasts than female viewers. Above are the general findings related to the changing attitude towards breaking news of terrorist acts.

\section{Recommendation for Future Research}

This study has provided a baseline study on the effects of TV breaking news related to terrorist acts on viewer's attitude. It has explored only effects of TV breaking news of terrorist acts in general, however the researchers have planned to work in future on more specific aspects and evaluate effects on more demographic characteristics. There is need to gauge the effects on different income or heavy or light viewers. In present research survey method is used but in future researchers used case study and other methods in it. In future, researchers can also finds the effects on children. And also find the effects under by using the conspiracy theory.

\section{References}

1. Carnagey NL, Anderson CA, Bushman (2006) The effect of video game violence on physiological desensitization to real life violence. Journal of experimental social psychology 43: 489-496.

2. Bushman BJ, Anderson CA (2009) comfortably numb: Desensitization effects of violent media on helping others. A Journal of the Association for Psychological Science.

3. Anderson CA, Berkowitz L, Donnerstein E, Huesman LR, Johnson JD, et al. (2003) The Influence Media on Youth Psycological Science in the Public Interest, Vol. 6.

4. Huesmann LR (2007) The impact of Electronic media: Scientific theory and research. Journal of adolescent health, Vol. 41.

5. Barthlow BD, Bushman BJ, Sestir MA (2005) Chronic violent video games exposure and desensitation to violent: Behavioral and event-related brain potential data. Journal of Experimental Social Psychology 42: 532-539. 
Citation: Iqbal A (2017) Role of Media Creating Desensitization among Viewers Related to Terrorist Acts. Arts Social Sci J 8: 297. doi: 10.4172/21516200.1000297

Page 9 of 9

6. Funk JB, Baldacci HB, Pasold T, Baumgardner J (2004) Violence Exposure in real life, videogames, television, movies and the internet: Is there Desensitization? Journal of Adolesence 27: 23-39.

7. Cantors J (2000) Media Violence and children's Emotions beyond the "Smoking" Paper presented at the Annual Convention of the American Psychology Association, Washington DC.

8. Scharrer E (2008) Media Exposure and Sensitivity to Violence in News reports Evidence of Desensitization. Journalism and Mass Communication, p: 85.

9. Krahe B, Millar I (2011) Desensitization to media violence: Links with habitual media violence exposure, aggressive conditions and aggressive behaviour, Journal of personality and social psychology 100: 630-646.

10. AkramJ (2009) Desensitization of Pakistani society: myth or reality.

11. Lawrence NW (2014) Social research methods quantitative and qualitative approaches: fourth edition, University of Wisconsin at white-water.
12. Shaughnessy OM, Stadler J (2012) Media and society an introduction, second edition, Oxford university press.

13. Katib K, Ejaz S (2010) Role of media in Pakistan Faculty of management science International Islamic University, Islamabad.

14. Alexandra L (2006) Violent Video Games Numb Children.

15. Chandler D (1995) Cultivation theory.

16. About the Handwritten Newspapers Project (2011)

17. Elon university of school, imaging the internet, A history and forecast.

18. Kaniz M (2013) Importance of television in our life.

19. The growth and expansion of Radio, Television and Film (2012) in Pakistan. 